Physics International 2 (1): 1-7, 2011

ISSN 1948-9803

(C) 2011 Science Publications

\title{
New Approach between the Optical Basicity and the Dielectric Constant through the Molar Polarizability for Some Binary Glasses
}

\author{
El-Sayed Moustafa \\ Department of Physics, Faculty of Science, \\ El-Azaher University, Assuit, 71452, Egypt
}

\begin{abstract}
Problem statement: In the present study, a new correlation between the optical basiciry which describes the electronic charge clouds around the oxide glass and the dielectric constant has been proposed through the molar polarizability of the binary oxide glasses. Approach: Two experimental forms have been suggested relating the optical basicity and the molar electronic polarizability. Hence, the dielectric constant and the optical basicity for some binary glass systems can be deduced. Results: The molar polarizability and the dielectric constant of these glasses exhibit a linear relation as represented with the optical basicity. We have applied the proposed relation on the binary glasses. Conclusion: It was found that a good agreement as the values determined with experimental results determined by previous researchers.
\end{abstract}

Key words: Dielectric constant, optical basicity, molar polarizability, binary glass systems, linear relation, oxide glasses, optical basicity, binary glasses, electronic charge, experimental results, electronic polarizability

\section{INTRODUCTION}

Glasses are very interesting for their potential applications in industry and many applied areas. Recently many researchers studied glasses as switching and memory devices, superior insulators and dielectrics. Thus glass becomes an ordinary electronic material (Khor et al., 2009; Varshneya, 1994).

The dielectric constant of a material is one of the most important factors for the electronic charge carriers and impurities in insulators. The dielectric constant of a solid may be expressed in terms of the polarizability of its constituent atoms $\alpha_{\mathrm{i}}$ (Verma et al., 2009; Nag, 1994; Xue et al., 2000; Marquez and Rinocon, 1995; Moustafa, 2011) as follows Eq. 1:

$$
\varepsilon_{\infty}=\frac{\left[1+\sum \mathrm{N}_{\mathrm{i} i} \alpha_{\mathrm{i}} / \varepsilon_{0}\right]}{\left[1-\sum \frac{\gamma \mathrm{N}_{\mathrm{i}}{ }_{\mathrm{i}}}{\varepsilon_{0}}\right]}
$$

where, $\mathrm{N}_{\mathrm{i}}$ is the number of atoms of species i per unit volume, $\varepsilon_{0}$ is the free space permittivity and $\gamma$ is the Lorenz factor. Recently, Xui et al. (2000) have proposed a formula as follows Eq. 2:

$\varepsilon_{\infty}=\mathrm{a}-\mathrm{b} Z_{\mathrm{A}}$
Where:

$\mathrm{a}$ and $\mathrm{b}=$ Constants depend on the compounds of material $\mathrm{Z}_{\mathrm{A}} \quad=$ The atomic number of cation

The prediction of the values of polarizability and the dielectric constant by theoretical methods has made significant contributions and open an active fields for new nonlinear glasses. The molar electronic polarizability is one of the most important properties of materials, which is closely related to its applicability in the field of electronics. In this connection the polarizability approach has been systematically developed in recent researches concerning the origin of molar electronic polarizability and optical basicity for simple oxide glasses (Zhao et al., 2007; Dimitrov and Komatsu, 1999).

In the frequency range of optical phenomena the dielectric constant $\varepsilon_{\infty}$ is due to mainly from the electronic polarizability. In this region the equations of LorenzLorenz and Clousis Mousstti (Chimalawong et al., 2010) are valid as follows Eq. 3:

$$
\propto_{\mathrm{m}}=\frac{\left(\varepsilon_{\infty}-1\right) \mathrm{M} * 10-24}{\left(\varepsilon_{\infty}-2\right) \sigma * 2.53}
$$

Where:

$M=$ The molecular weight of the glass system

$\sigma=$ The density of glass

(C) 2011 El-Sayed Moustafa. This open access article is distributed under a Creative Commons Attribution (CC-BY) 3.0 license which permits unrestricted use, distribution, and reproduction in any medium, provided the original work is properly credited. DOI: 10.3844/pisp.2011.1.7 


\section{MATERIALS AND METHODS}

Electronic polarizability of ions demonstrates the way of their electronic clouds distributed by applying electric field. It is closely related to many properties of the glass systems such as the optical basicity (Dimitrov and Komatsu, 2010) and refraction, hence the dielectric constant. Recently studies have shown a relationship between refractivity and optical basicity for oxide glasses over a modest range of $\Lambda_{\text {th }}$ (Dimitrov and Komatsu, 1999).

Using electronic polarizabiliy, $\alpha_{\mathrm{m}}$, is more detectable than the refractivity. It is found that there is a good linearity between the oxide ion polarizability over a very wide range of $\Lambda$ for oxide materials generally (Dimitrov and Komatsu, 1999).

So it is necessary to know knowledge about the state of polarization of the ions in glassy materials using the optical basicity which describes the electronic charge cloud around these ions. The theoretical optical basicity of the glass is given by Eq. 4 (Vithal et al., 1997):

$$
\Lambda=1-\sum_{\mathrm{i}}\left(\frac{\mathrm{Z}_{\mathrm{i}} \mathrm{r}_{\mathrm{i}}}{2}\right)\left(1-\frac{1}{\gamma_{\mathrm{i}}}\right)
$$

Where:

$\mathrm{Z}_{\mathrm{i}}=$ The valence of the ith cation

$r_{i}=$ The ratio of the number of the ith cations to that of oxide ions

$y_{i}=$ The basicity moderating parameter given by Eq. 5 :

$\gamma_{i}=1.36\left(\gamma_{i}-0.26\right)$

where, $\gamma_{i}$ is the Pauling, s electronegativity of the ith atom.

There are four components of contributions of the molar polarizability: electronic, ionic, dipolar and interfacial. The electronic contribution is the movement of negative electrons in the electric field. The ionic contribution is the displacement of charged ions relative to each others. The main contribution is due to the electronic polarizability in the range under test in our work.

Recently many researches has been done (Verma et al., 2009) on the binary glass systems ,which based on the experimental data, The advantage of the empirical forms allow a broad band of works to obtain useful properties and trends become more clear.

The main idea of this study is that the observed linear relation between the molar polarizability and the optical basicity, consequently the dielectric constant for binary glasses. The aim of the present study is to suggest a correlation between the optical basicity and the dielectric constant for binary glasses.

\section{RESULTS}

Firstly, the experimental reported data of the molar polarizability have been represented against the value of the theoretical optical basicity.

Figure 1-6 shows the correlation between the optical basicity and the molar electronic polarizability. To obtain a good agreement with the experimental results, we proposed the following form as Eq. 6:

$\alpha_{\mathrm{m}}=\mathrm{a} \Lambda_{\mathrm{th}}+\mathrm{c}$

where, a and $\mathrm{c}$ are constants depends on the structure of the glass system, with respect to Fig. 1-6, the relation is a good linear relation for almost binary and simple oxides glasses.

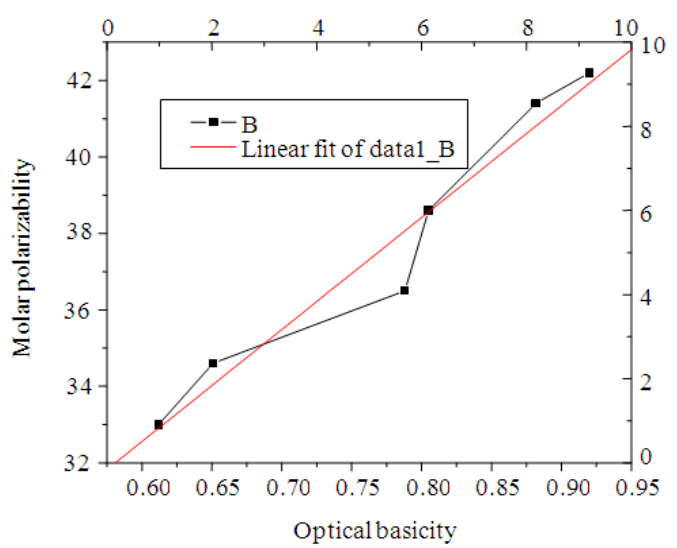

Fig. 1: The relationship between the optical basicity and the molar polarizabilityin case of $\mathrm{Bi}_{2} \mathrm{O}_{3}-\mathrm{B}_{2} \mathrm{O}_{3}$ glass

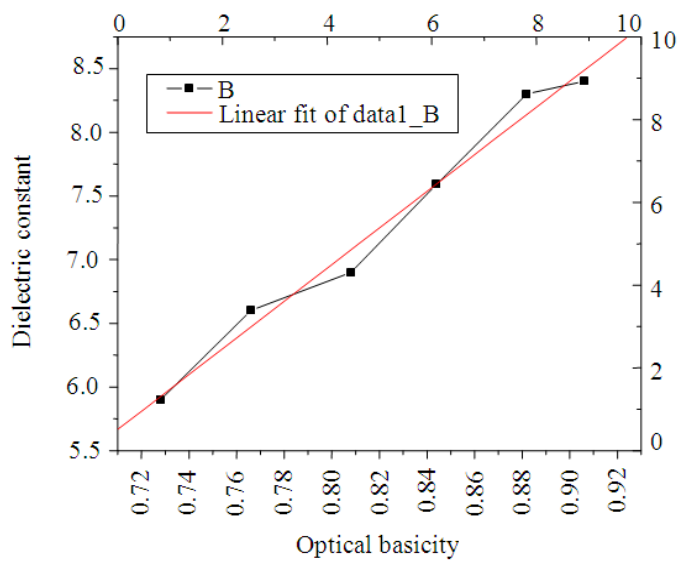

Fig. 2: The relationship between the optical basicity and the molar polarizability in in case of $\mathrm{Bi}_{2} \mathrm{O}_{3}-\mathrm{B}_{2} \mathrm{O}_{3}$ glass 


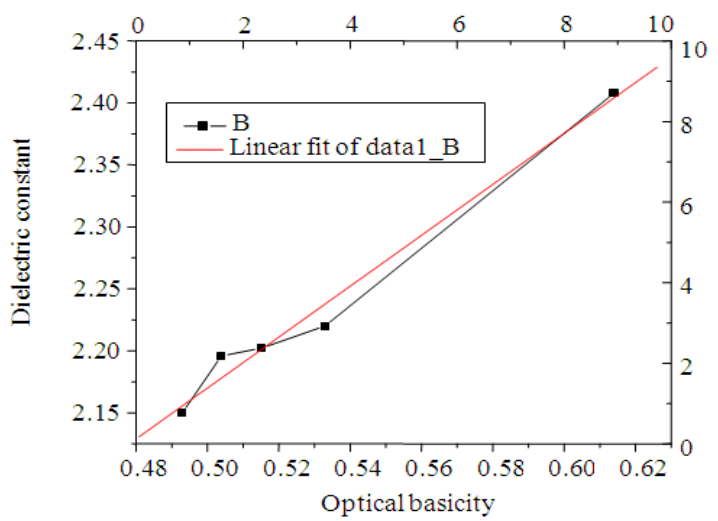

Fig. 3: The relation between the optical basicity and the molar polarizability in case of $\mathrm{GeO}_{2}-\mathrm{SiO}_{2}$ glass increasing $\mathrm{GeO}_{2}$

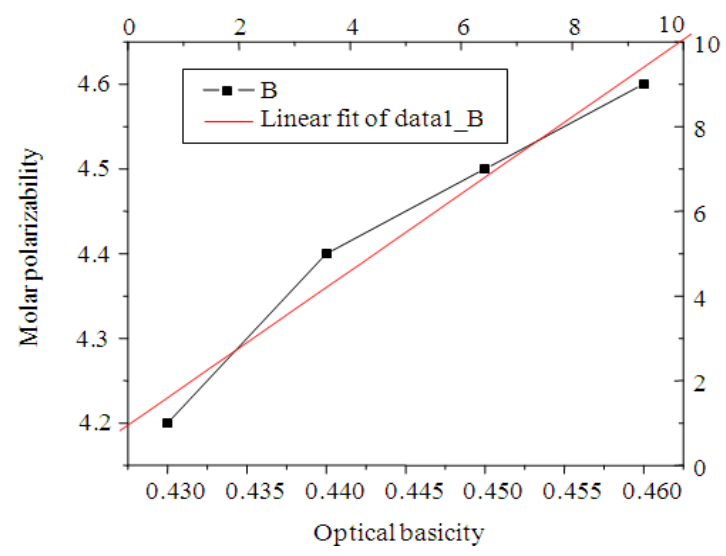

Fig. 4: The relation between the optical basicity and the molar polarizability in case of $\mathrm{GeO}_{2}-\mathrm{B}_{2} \mathrm{O}_{3}$ glass increasing $\mathrm{GeO}_{2}$

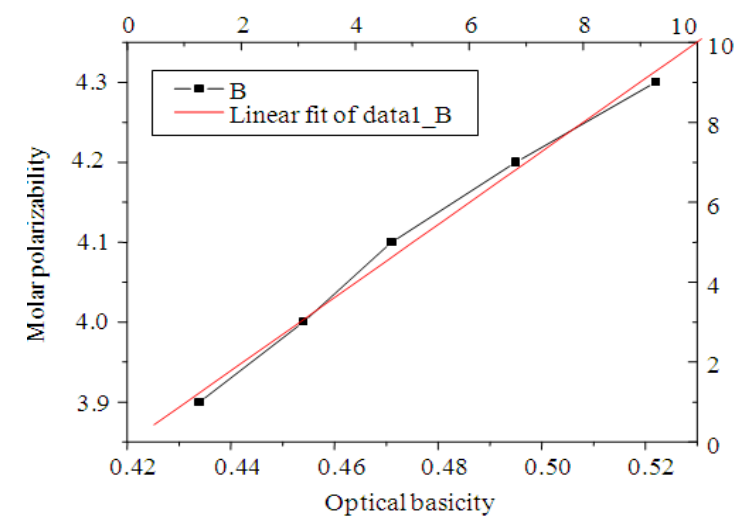

Fig. 5: The relation between the optical basicity and the molar polarizability in case of $\mathrm{K}_{2} \mathrm{O}-\mathrm{B}_{2} \mathrm{O}_{2}$ glass increasing $\mathrm{KO}_{2}$

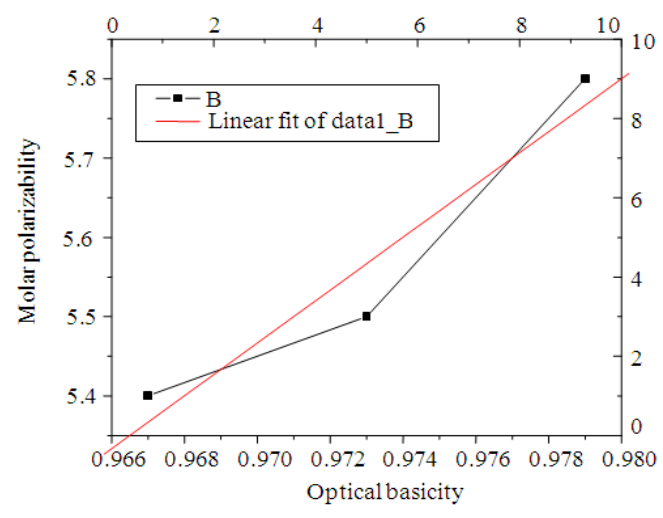

Fig. 6: The relation between the optical basicity and the molar polarizability in case of $\mathrm{MgO}-\mathrm{TeO}_{2}$ glass increasing $\mathrm{MO}$

Secondly, the experimental reported data of the dielectric constant have been represented against the value of the theoretical optical basicity.

\section{DISCUSSION}

Investigating carefully Fig. 7-18, it is easy clear to note that the dielectric constant $\left(\varepsilon_{\infty}\right)$ increases with increasing the optical basicity $\left(\Lambda_{\mathrm{th}}\right)$.

Comparing the behavior of the dielectric constant and the optical basicity with the behavior of the molar polarizability $\alpha_{\mathrm{m}}$ and $\Lambda_{\mathrm{th}}$, we can conclude that these above behaviors agree with the Claussis-Mossotti equation, which relates $\varepsilon_{\infty}$ and $\mathrm{a}_{\mathrm{m}}$. It is well known that as the molar polarizability increases the dielectric constant of the glass increases (Verma et al., 2009).

In the present work, a microscopic and analytical vision proposed for almost binary oxide glasses, which correlates the relation between the dielectric constant of these glasses and the optical basicity in the range of optical phenomena.

Dimitrov and Komatsu (1999) had established that there are linear relationship between the optical basicity and the oxide ion polarizability for binary oxide glasses. So it is logically and predicted that there are a linear relation between $\alpha_{\mathrm{m}}$ and $\Lambda_{\mathrm{t}}$, because the molar polarizability is the sum of cation and oxide ion polarizabilities.

To obtain a good agreement between the theoretical and experimental results for binary oxide glasses, an empirical form was proposed according to the trend of the experimental data between $\varepsilon_{\infty}$ and $\Lambda_{\mathrm{th}}$ as the following Eq. 7:

$$
\varepsilon_{\infty}=\mathrm{A}+\mathrm{B}^{*} \Lambda_{\mathrm{th}}
$$


Phy. Intl. 2 (1): 1-7, 2011

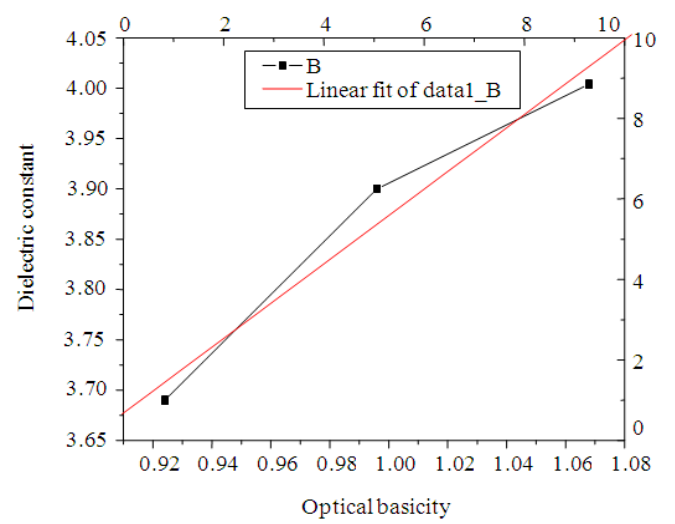

Fig. 7: The relation between the optical basicity and the dielectric constant in case of $\mathrm{SB}_{2} \mathrm{O}_{3}-\mathrm{B}_{2} \mathrm{O}_{3}$ glass increasing $\mathrm{SB}_{2} \mathrm{O}_{3}$

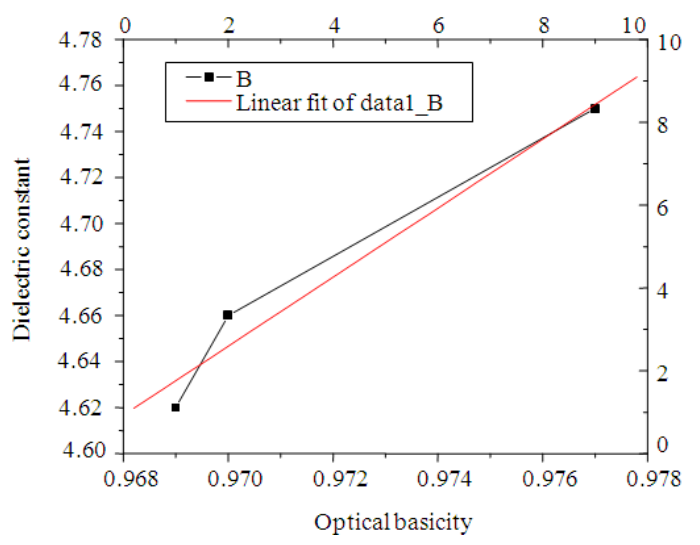

Fig.8: The relation between the optical basicity and the dielectric constant in case of $\mathrm{Ag}_{2} \mathrm{O}-\mathrm{TeO}_{2}$ glass with increasing $\mathrm{Ag}_{2} \mathrm{O}$

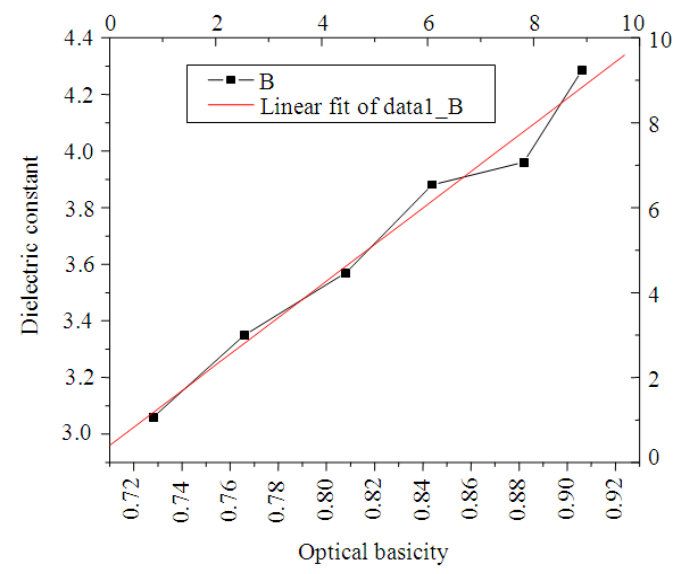

Fig. 9: The relation between the optical basicity and the dielectric polarizability in case of $\mathrm{Bi}_{2} \mathrm{O}_{3}-\mathrm{SiO}_{2}$ glass increasing $\mathrm{Bi}_{2} \mathrm{O}_{3}$

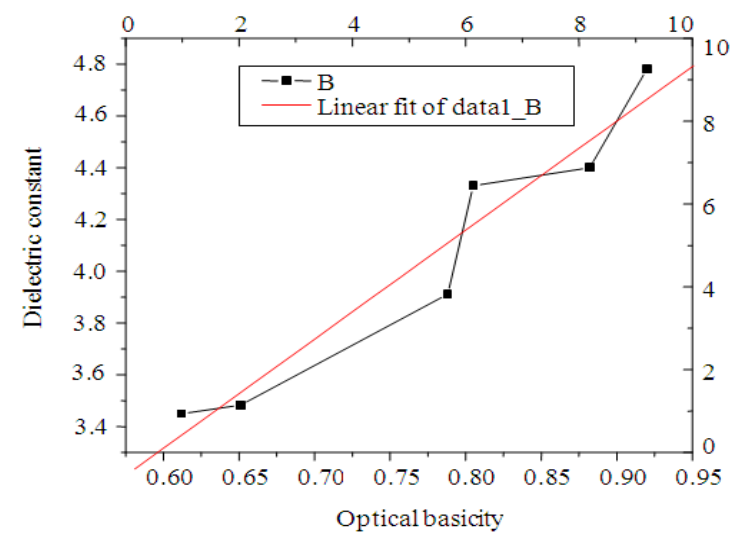

Fig. 10: The relation between the optical basicity and the dielectric polarizability in case of $\mathrm{Bi}_{2} \mathrm{O}_{3^{-}}$ $\mathrm{B}_{2} \mathrm{O}_{3}$ glass increasingal $\mathrm{Bi}_{2} \mathrm{O}_{3}$

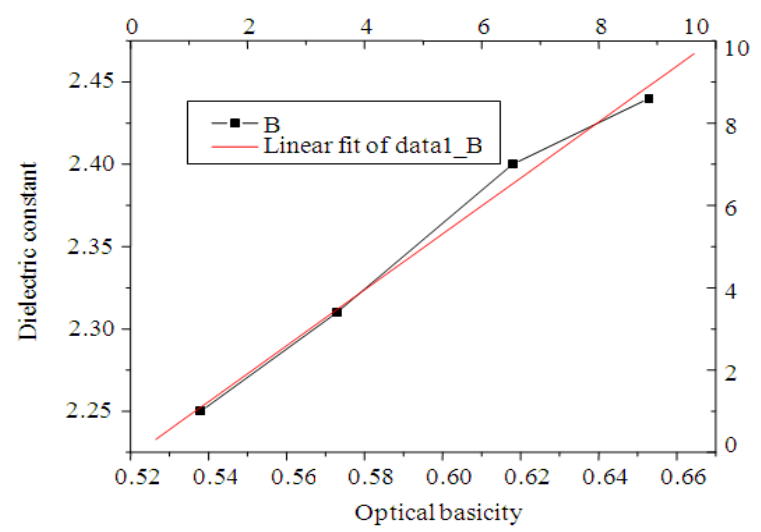

Fig. 11: The relation between the optical basicity and dielectric constant in case of $\mathrm{LiO}_{2}-\mathrm{SIO}_{2}$ glass increasing $\mathrm{LiO}_{2}$

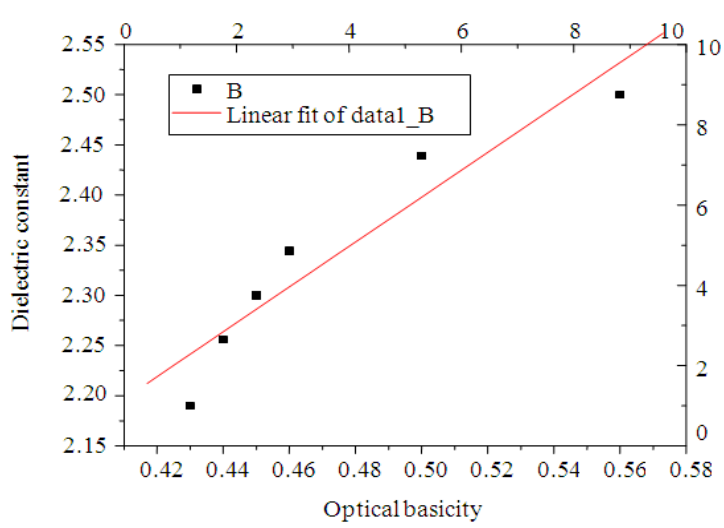

Fig. 12: The relation between the optical basicity and the dielectric constant in case of $\mathrm{GeO}_{2}-\mathrm{B}_{2} \mathrm{O}_{3}$ glass increasing $\mathrm{GeO}_{2}$ 


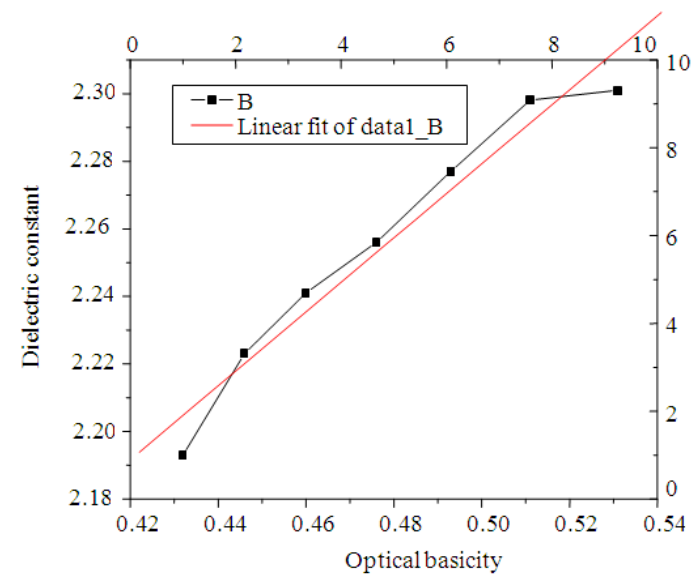

Fig.13: The relation between the optical basicity and the dielectric constant in case of $\mathrm{Na}_{2} \mathrm{O}-\mathrm{B}_{2} \mathrm{O}_{3}$ glass increasing $\mathrm{Na}_{2} \mathrm{O}$.

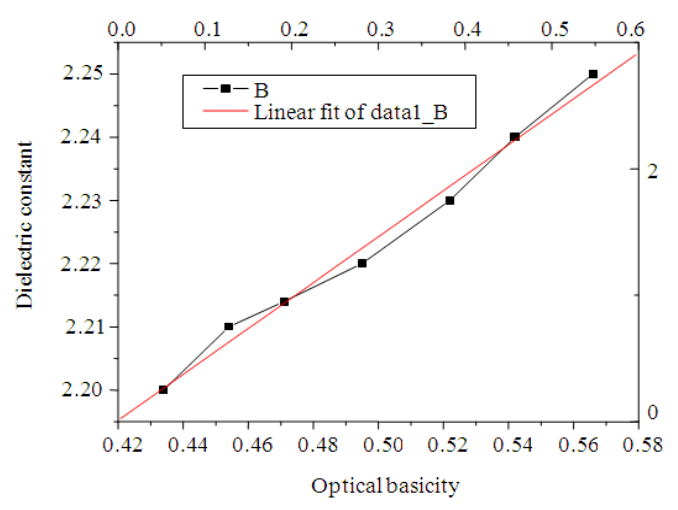

Fig. 14: The relation between the optical basicity and the dielectric constant in case of $\mathrm{K}_{2} \mathrm{O}-\mathrm{B} 2 \mathrm{O} 3$ glass increasing $\mathrm{K}_{2} \mathrm{O}$.

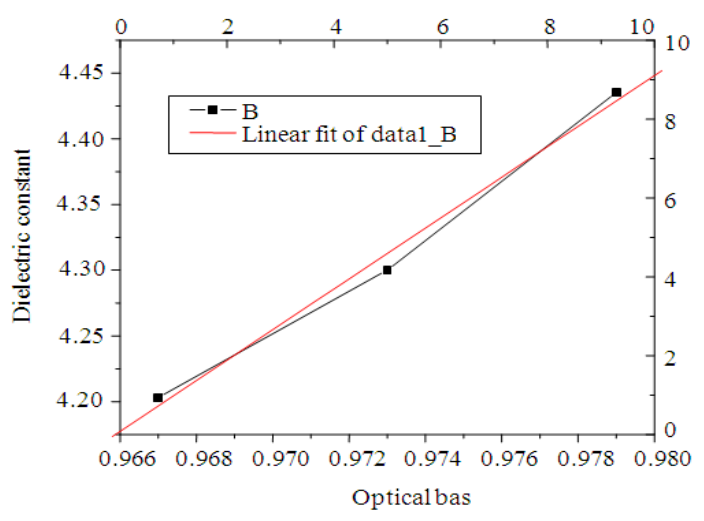

Fig. 15: The relation between the optical basicity and the dielectric constant in case of $\mathrm{MgO}-\mathrm{B}_{2} \mathrm{O}_{3}$ glass increasing $\mathrm{MgO}$

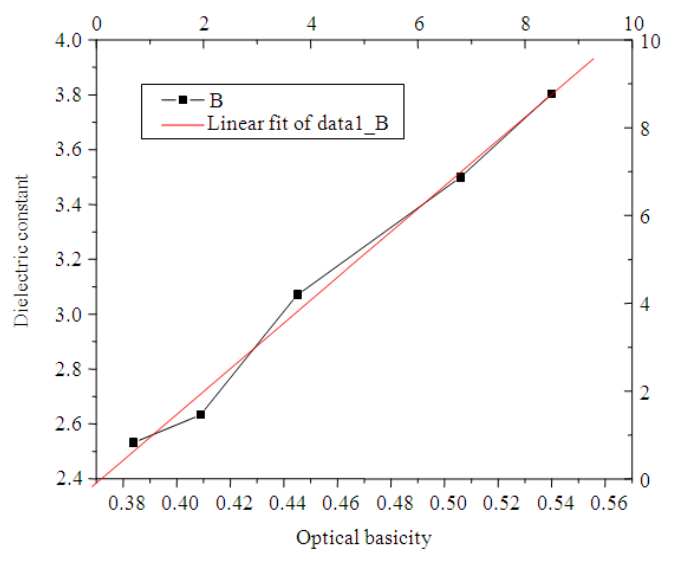

Fig. 16: The relation between the optical basicity and the dielectric constant in case of $\mathrm{Bi}_{2} \mathrm{O}_{3}-\mathrm{P}_{2} \mathrm{O}_{3}$ glass with increasing $\mathrm{Bi}_{2} \mathrm{O}_{3}$

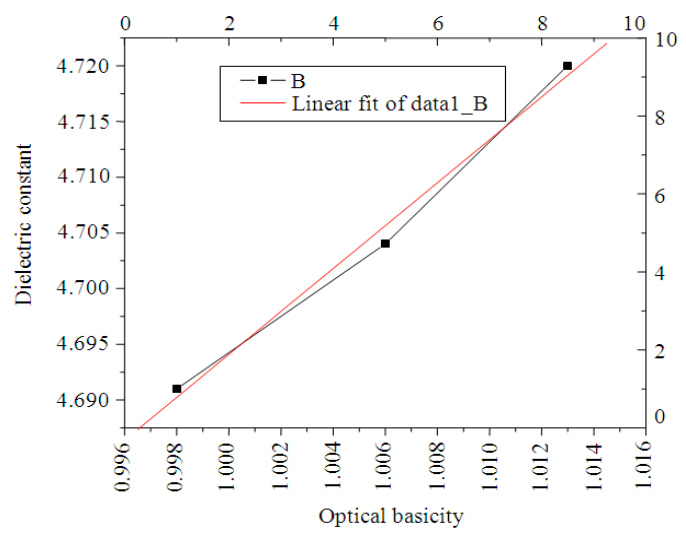

Fig. 17: The relation between the optical basicity and the dielectric constant in case of Wo3-TeO2 glass increasing Wo3

Table 1: Illustrates the values of constants in the proposed equation of the dielectric constant of the glasses as a function of the optical basicity

\begin{tabular}{ll}
\hline Constants & $\begin{array}{l}\text { Glass system } \\
\mathrm{A}_{\mathrm{p}} \mathrm{O}_{\mathrm{q}}-\mathrm{B}_{\mathrm{r}} \mathrm{O}_{\mathrm{s}}\end{array}$ \\
\hline $\mathrm{A}$ & $0.5-2.5$ \\
$\mathrm{~B}$ & $1-3$ \\
\hline
\end{tabular}

Table 2: Illustrates the values of constants in the proposed formula of the dielectric constant of the glasses as a function of the optical basicity.

\begin{tabular}{|c|c|c|}
\hline \multirow[b]{2}{*}{ Type of glass system } & \multicolumn{2}{|c|}{ Constants } \\
\hline & A & $\mathrm{B}$ \\
\hline Borates & 2.00 & 2.50 \\
\hline Silicates & 1.33 & 1.70 \\
\hline Germanates & 1.14 & 2.10 \\
\hline Tellurates & 1.60 & 2.99 \\
\hline Phosphates & 1.60 & 3.00 \\
\hline Titanates & 0.50 & 3.00 \\
\hline
\end{tabular}


Phy. Intl. 2 (1): 1-7, 2011

Table 3: Comparison between the calculated and experimental reported values of the dielectric constant $\left(\varepsilon_{\infty}\right)$ for some binary glass systems

\begin{tabular}{llll}
\hline Type of glass system & $\begin{array}{l}\text { Theoretical optical } \\
\text { basicity } \Lambda_{\text {th }}\end{array}$ & $\begin{array}{l}\text { Calculated } \\
\text { values } \varepsilon_{\infty, \text { Cal }}\end{array}$ & $\begin{array}{c}\text { Experimental } \\
\text { reported values } \varepsilon_{\infty}\end{array}$ \\
\hline $0.7 \mathrm{Sb}_{2} \mathrm{O}_{3}-0.3 \mathrm{~B}_{2} \mathrm{O}_{3}$ & 0.924 & 3.700 & 3.530 \\
$0.65 \mathrm{Bi}_{2} \mathrm{O}_{3}-0.35 \mathrm{~B}_{2} \mathrm{O}_{3}$ & 0.920 & 4.990 & 4.840 \\
$0.6 \mathrm{GeO}_{2}-0.4 \mathrm{SiO}_{2}$ & 0.614 & 2.410 & 2.404 \\
$0.05 \mathrm{Cs}_{2} \mathrm{O}-0.95 \mathrm{SiO}_{2}$ & 0.511 & 2.192 & 2.193 \\
$0.1 \mathrm{~K}_{2} \mathrm{O}-0.9 \mathrm{~B}_{2} \mathrm{O}_{3}$ & 0.495 & 2.220 & 2.230 \\
$0.1 \mathrm{Bi}_{2} \mathrm{O}_{3}-0.9 \mathrm{GeO}_{2}$ & 0.765 & 2.714 & 2.940 \\
$0.1 \mathrm{~V}_{2} \mathrm{O}_{5}-0.9 \mathrm{GeO}_{2}$ & 0.774 & 2.732 & 2.822 \\
$0.1 \mathrm{MoO}_{3}-0.9 \mathrm{TeO}_{2}$ & 1.001 & 4.440 & 4.473 \\
$0.1 \mathrm{Wo}_{3}-0.9 \mathrm{TeO}_{2}$ & 0.998 & 4.500 & 4.660 \\
$0.05 \mathrm{TaO}_{2}-0.95 \mathrm{TeO}_{2}$ & 0.987 & 4.462 & 4.682 \\
$0.33 \mathrm{~K}_{2} \mathrm{O}-0.77 \mathrm{TiO}_{2}$ & 1.047 & 3.610 & 3.312 \\
$0.20 \mathrm{PbO}_{2}-8 \mathrm{TiO}_{2}$ & 0.994 & 3.500 & 4.120 \\
$0.2 \mathrm{Li}_{2} \mathrm{O}-0.8 \mathrm{SiO}_{2}$ & 0.538 & 2.440 & 2.250 \\
$0.1 \mathrm{MgO}_{2}-9 \mathrm{TeO}_{2}$ & 0.979 & 4.400 & 4.435 \\
$0.10 \mathrm{Bi}_{2} \mathrm{O}_{3}-0.9 \mathrm{P}_{2} \mathrm{O}_{3}$ & 0.384 & 2.300 & 2.530 \\
$0.05 \mathrm{Na}_{2} \mathrm{O}-0.95 \mathrm{~B}_{2} \mathrm{O}_{3}$ & 0.432 & 2.200 & 2.193 \\
\hline
\end{tabular}

( Note: $\mathrm{n}^{2}=\varepsilon_{\infty}$ )

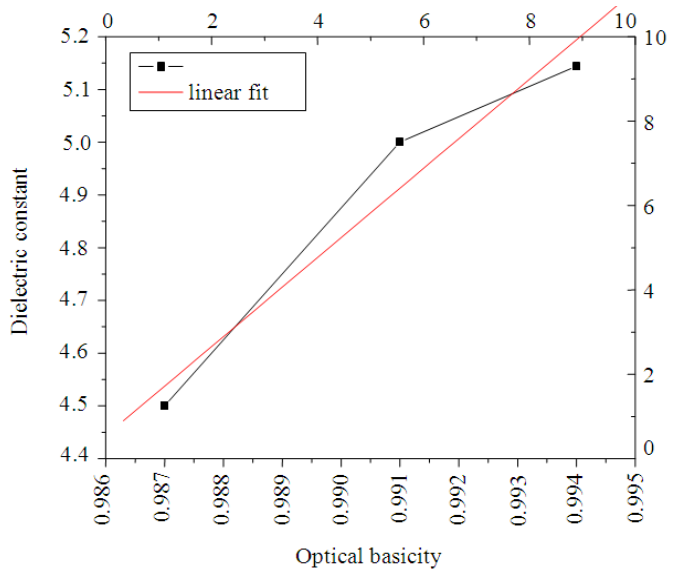

Fig. 18: The relation between the optical basicity and the dielectric constant in case of $\mathrm{pbO}-\mathrm{TiO}_{2}$

A and B are constants depends on the compounds of the glass system i.e., as the weight number of the cations in the glass system increases the values $\mathrm{A}, \mathrm{B}$ increase such as in system $\mathrm{pb}_{2} \mathrm{O}-\mathrm{TiO}_{2}$ and $\mathrm{Wo}_{3}-\mathrm{TeO}_{2}$ as illustrated in Table 2. A useful comparison are shown in Table 3, it is obvious that the calculated values of $\varepsilon_{\infty}$ is satisfied relative to the experimental values and this share to predict new binary glasses.

\section{CONCLUSION}

Advantage correlation and an empirical form have been proposed for the dielectric constant determination through the theoretical optical basicity for binary oxide glasses. The relation between the molar polarizability and optical basicity has been established as a linear relation in all binary oxide glasses. It was found that for certain system of glass, the above relation can be represented as linear form. So we can determine unknown value of the molar polarizability by the corresponding value of the theoretical optical basicity simply. Also the dielectric constant of binary glasses can be evaluated in the field of optical frequency phenomena, especially the determination of the dielectric constant that requires more sensitive experimental set-up in that region of that frequency. This can be achieved by applying the proposed form (7). Finally more nonlinear binary glasses can be predicted through the estimated electronic molar polarizability.

\section{REFERENCES}

Chimalawong, P., J. Kaewkhao and P. Limsuwan, 2010. Optical investigation and electronic polarizability of $\mathrm{Nd}^{3+}$ doped soda-lime-silicate glasses. Energy Res. J., 1: 176-181. DOI: 10.3844/erjsp.2010.176.181

Dimitrov, V. and T. Komatsu, 1999. Electronic polarizability, optical basicity and non-linear optical properties of oxide glasses. J. Non-Crystal. Solids, 249: 160-179. DOI: $10.1016 /$ S00223093(99)00317-8

Dimitrov, V. and T. Komatsu, 2010. An interpretation of optical properties of oxides and oxide glasses in terms of the electronic ion polarizability and average single bond strength. J. Univ. Chem. Technol. Metall., 45: 219-250.

Khor, S.F., Z.A. Talib, H.A.A. Sidek, W.M. Daud and B.H. Ng, 2009. Effects of $\mathrm{ZnO}$ on dielectric properties and electrical conductivity of ternary zinc magnesium phosphate glasses. Am. J. Applied Sci., $\quad 6$ : $1010-1014 . \quad$ DOI: 10.3844/ajassp.2009.1010.1014 
Marquez, R. and C. Rinocon, 1995. On the dielectric constants of $\mathrm{A}^{\mathrm{I}} \mathrm{B}^{\mathrm{III}} \mathrm{C}$ chalcopyrite semiconductor compounds. Phys. Status Solid, 191: 115-119. DOI: $10.1002 / p s s b .2221910112$

Moustafa, E.S., 2011. Accurate determination of nonlinear refractive index for some binary glass systems. Am. J. Applied Sci., 8: 33-38. DOI: 10.3844/ajassp.2011.33.38

Nag, B.R., 1994. Empirical formula for the dielectric constant of cubic semiconductors. Applied Phys. Lett., 65: 1938-1939. DOI: 10.1063/1.112823

Verma, A.S., R.K. Singh and S.K. Rathi, 2009. An empirical model for dielectric constant and electronic polarizability of binary $\left(\mathrm{A}^{\mathrm{N}} \mathrm{B}^{8-\mathrm{N}}\right)$ and ternary $\left(\mathrm{A}^{\mathrm{N}} \mathrm{B}^{2+\mathrm{N}} \mathrm{C}_{2}{ }^{7-\mathrm{N}}\right)$ tetrahedral semiconductors. J. Allo. Compoun., 486: 795-800. DOI: 10.1016/j.jallcom.2009.07.067
Varshneya, A.K., 1994. Fundamentals of Inorganic Glasses. 1st Edn., Academic Press, Boston, ISBN10: 0127149708, pp: 570.

Vithal, M., P. Nachimuthu, T. Banu and R. Jagannathan, 1997. Optical and electrical properties of $\mathrm{PbO}-\mathrm{TiO}_{2}, \mathrm{PbO}-\mathrm{TeO}_{2}$ and $\mathrm{PbO}-\mathrm{CdO}$ glass systems. J. Applied Phys., 81: 7922-7926. DOI: $10.1063 / 1.365366$

Xue, D., K. Betzler and H. Hesse, 2000. Dielectric constants of binary rare-earth compounds. J. Phy. Condens. Matte., 12: 3113-3118.

Zhao, X., X. Wang, H. Lin and Z. Wang, 2007. Correlation among electronic polarizability, optical basicity and interaction parameter of $\mathrm{Bi}_{2} \mathrm{O}_{3}-\mathrm{B}_{2} \mathrm{O}_{3}$ glasses. Phys. B.: Condensed Matter, 390: 293300. DOI: $10.1016 /$ j.physb.2006.08.047 